\title{
A qualidade da educação superior em contexto emergente: uma aproximação na perspectiva da produção acadêmica recente $(2007-2017)$
}

\author{
The quality of higher education in an emerging context: an approximation in the \\ perspective of recent academic production (2007 - 2017)
}

La calidad de la educación superior en contexto emergente: una aproximación en la perspectiva de la producción académica reciente $(2007$ - 2017)

\begin{abstract}
Resumo: Neste artigo, buscamos sistematizar a produção do conhecimento, entre o período de 2007 e 2017, sobre o tema Qualidade da Educação Superior, a fim de compreender como é este apresentado pelas comunidades de pesquisa inseridas junto aos Programas de Pós-Graduação stricto sensu brasileiros. $\mathrm{Na}$ produção dos dados, utilizamos os princípios de Estado de Conhecimento, com foco na pesquisa de caráter exploratório, inventariante e descritivo. Como resultados, temos a qualidade percebida a partir da excelência universitária, da formação dos sujeitos e da missão da Universidade junto à sociedade.
\end{abstract}

Palavras-chave: Educação Superior, Qualidade da Educação, Contextos Emergentes, Estado do Conhecimento.

Abstract: In this article, we seek to systematize the production of knowledge between the period 2007 and 2017 on the topic of Higher Education Quality, in order to understand how it is presented by the research communities inserted in the stricto sensu Brazilian Postgraduate Programs. In the data production, we use the principles of Knowledge State, with a focus on the research of an exploratory, inventorying and descriptive character. As a result, we have the quality perceived from the university excellence, the training of the subjects and the mission of the University with society.

Keywords: Higher Education, Quality of Education, Emerging Context, Knowledge State.

Resumen: En este artículo, buscamos sistematizar la producción del conocimiento, entre el período de 2007 y 2017, sobre el tema Calidad de la Educación Superior, a fin de comprender cómo el mismo es presentado por las comunidades de investigación insertadas junto a los Programas de Postgrado stricto sensu brasileños. En la producción de los datos, utilizamos los principios 
de Estado de Conocimiento, con foco en la investigación de carácter exploratorio, inventariante y descriptivo. Como resultados, tenemos la calidad percibida a partir de la excelencia universitaria, de la formación de los sujetos y de la misión de la Universidad junto a la sociedad.

Palabras clave: Educación Superior, Calidad de la Educación, Contextos Emergentes, Estado del Conocimiento.

\section{INTRODUÇÃO}

A Educação Superior se constitui como um complexo, mutável dentro do Sistema Educacional brasileiro, especialmente se pensarmos a forma como esse nível de educação se mostra permeável em meio à diversidade de cenários nos quais essa educação se insere frente às exigências do mundo contemporâneo, à luz de novas formas de ser e estar no mundo, à velocidade e à forma de produção de conhecimento, e ao avanço dos processos de internacionalização destes processos (SOBRINHO, 2010). Nessa perspectiva, a Educação Superior acaba constituindo-se, dentro de um ideário bourdiniano, como um "campo de disputas" (CORTESÃO; STOER, 2002, p. 381), como uma verdadeira "rede, ou uma configuração de relações objetivas entre posições" (BOURDIEU, 1988, p. 72). Podemos ainda caracterizar esse "campo de disputas" a partir dos discursos que se mostram hegemônicos em tempos e espaços distintos na consolidação desse campo, principalmente aqueles que trazem a reflexão de seu papel junto á Sociedade do Conhecimento (MOROSINI, 2014).

A partir do final do século XIX e início do século XX, a Educação Superior acaba ganhando um papel de destaque junto aos contextos locais e globais nas diferentes nações, pois esse nível da educação acaba por adentrar o movimento estratégico de expansão da economia destes países, especialmente os situados no Global-Norte ${ }^{1}$ (MOROSINI, 2011), destacando-se a capacitação em nível superior de profissionais que atendam às novas demandas do emergente mundo do trabalho. No Brasil, esse movimento pode ser percebido a partir de uma série de políticas, programas e ações de fomento à expansão da Educação Superior, acordos bilaterais e multilaterais, bolsas para capacitação de brasileiros no exterior, presença de estrangeiros em Instituições de Ensino Superior nacionais, no alcance da tão sonhada excelência, traduzida dentro da perspectiva trazida no conceito de qualidade (CUNHA, 2017).

\footnotetext{
1 Segundo Fontoura (2018, p. 153), "Esta divisão não carrega em si apenas a divisão territorial geográfica, esta forma de olhar o globo emerge do Pós-Guerra Fria onde o mundo deixa de ser percebido na perspectiva socialista e capitalista, passando então a ser operado na lógica dos desenvolvidos (países com processos de industrialização consolidados - Global-Norte) e aqueles em desenvolvimento (países formados a partir de ex-colônias, que implementaram tardiamente seu processo de industrialização - Global-Sul)".
} 
A ideia de qualidade da educação não se apresenta de forma unânime dentro do conjunto no qual se situam as diferentes comunidades de pesquisa (em/sobre educação); nesse sentido, o termo deve ser percebido a partir de sua polissemia e de seu dinamismo, ou seja, a ideia de qualidade da educação se efetiva nos diferentes momentos históricos, imersos em um conjunto de influências situadas/localizadas sob determinado tempo e espaço legitimado (MOROSINI, 2014). Dessa forma, a qualidade da educação, emerge como um conceito mutável e repleto de contradições, admitindo uma certa multiplicidade de entendimentos. $\mathrm{O}$ uso do termo qualidade não possui delimitação semântica precisa ${ }^{2}$, o que possibilita o atendimento a diferentes demandas exigidas para além de um campo social (econômico, cultural, político, etc).

Como já apontamos anteriormente, a polissemia na semântica do termo, faz com que diferentes agentes de influência, disputem o discurso hegemônico que "normatizará" a ideia de qualidade junto às comunidades de pesquisa. Esse processo ocorre de diferentes formas; porém, da mesma forma que Morosini e Fernandes (2014), compreendemos que a escrita se coloca como uma importante ferramenta na produção e na socialização do conhecimento, "a escritura mais do que uma forma da comunicação humana, configura-se em condição de registro do vivido histórico, social e culturalmente e, assim da possibilidade de reescrever a escrita e o caminho por viver". Entendendo esse material como fonte de conhecimento, iniciamos o processo investigativo, por acreditarmos que o material bibliográfico produzido pelas diferentes comunidades de pesquisa, acaba por delimitar os contornos do próprio campo de investigação, além de indicarem, em uma última análise, o pensamento dessa comunidade de pesquisadores.

A partir desses apontamentos, esta investigação busca compreender a forma como os conceitos de qualidade da educação se materializam junto à produção acadêmica (teses e dissertações) dos últimos 10 anos (2007-2017), de Programas de Pós-Graduação stricto sensu brasileiros. Para isso, como estratégia metodológica na produção dos dados, utilizamos os princípios de Estado do Conhecimento (FERREIRA, 2002; MOROSINI, 2015), caracterizados pelo foco na pesquisa de caráter histórico-bibliográfico (FIORENTINI; LORENZATO, 2007), exploratório-investigativo (MELO, 2006), inventariante e descritivo (FERREIRA, 2002). O material empírico analisado por esta investigação foi disponibilizado pela Base de Dados da Biblioteca Brasileira de Teses e Dissertações do Instituto Brasileiro de Informação em Ciência e Tecnologia (BDTD/IBICT).

2 Como aponta Davok (2007, p. 507) ao evidenciar os diferentes contextos no qual o conceito de qualidade é consubstanciado: "Em economia e administração, por exemplo, qualidade tanto pode significar a relação entre as características e os procedimentos aplicados na fabricação ou desenvolvimento de um bem ou um serviço, como também o grau de satisfação do cliente para com o produto ou serviço adquirido em relação à sua expectativa inicial". 


\section{O ESTADO DO CONHECIMENTO COMO ESTRATÉGIA METODOLÓGICA NA APROXIMAÇÃO DO CAMPO DE ESTUDO}

O Estado do Conhecimento surge como importante ferramenta metodológica, já que a mesma possibilita diferentes aproximações com os mais diversos campos de investigação. Nas ciências humanas, os estados de conhecimento acabam ganhando lugar de destaque dentro das produções, em especial naquelas que objetivam compreender o pensamento científico presente junto a determinados colegiados de pesquisa. Segundo Morosini (2015, p. 101), a construção de Estado de Conhecimento surge como uma possibilidade na "identificação, registro, categorização que levem à reflexão e síntese sobre a produção científica de uma determinada área, em um determinado espaço de tempo". As pesquisas compreendidas como sendo de Estado do Conhecimento podem ser definidas em função de seu caráter bibliográfico e de seu compromisso de mapear e trazer para o debate a produção acadêmica em diferentes campos do saber, possibilitando, assim, a compreensão de aspectos e consequentemente as dimensões onde está produção bibliográfica se insere dentro do campo científico (FERREIRA, 2002).

O desenvolvimento de investigações que se fundamentam na perspectiva de produção de Estados de Conhecimento utiliza-se do rigor científico como procedimento metodológico em sua validação; dessa forma, destacamos a importância da metodologia no próprio entendimento dos resultados obtidos. Essa construção pressupõe, ainda, por parte do pesquisador, certo "trânsito" junto ao campo a ser investigado, entendendo-se por trânsito "domínio" do pesquisador sobre a temática investigada, domínio esse, por sua vez, podendo ser traduzido a partir de diferentes dimensões, como a experiência do pesquisador no desenvolvimento de investigações imersas na temática estudada, a percepção dos paradigmas imbricados na temática de estudo, possíveis politicas norteadoras das produções de caráter cientifico, bem como as fontes de publicação relevantes e a construção do caminho científico percorrido pelo tema ao longo do tempo.

Faz-se necessário considerar que a construção de uma produção científica está relacionada não só à pessoa/pesquisador que a produz, mas a influências da instituição na qual está inserida, do país em que vive e de suas relações com a perspectiva global. Em outras palavras, a produção está inserida no campo científico e, consequentemente, em suas regras constitutivas (MOROSINI, 2015, p. 102). 
Os Estados do Conhecimento se perfazem no cenário das pesquisas acadêmicas como uma alternativa no entendimento dos contextos em que as pesquisas nos mais variados e multiversos campos de estudo se inserem. A proposição da utilização de princípios de Estados de Conhecimento acaba sendo materializada a partir da metapesquisa (TELLO; MAINARDES, 2015), ou seja, uma análise sistemática do que vem sendo produzido no campo. Dessa forma, a metapesquisa se coloca junto a construção de Estados do Conhecimento como um procedimento no qual se extrai de um conjunto de bibliografias selecionado para um exame sistemático e crítico. Tello e Mainardes (2012; 2015), fazem uma distinção entre a metapesquisa, dos estudos nominados como de revisão de literatura e de Estados do Conhecimento; ressaltamos, porém, o aspecto organizacional e sistemático presente na metapesquisa, possibilitando-a como uma "ferramenta" de operacionalização do processo de construção dos Estados do Conhecimento, para além da postura crítica, interpretativa e da compreensão das perspectivas epistemológicas destacadas pelos autores.

Morosini (2015, p. 102) entende a construção dos Estados do Conhecimento partindo da "identificação, registro, categorização que levem à reflexão e síntese sobre a produção científica de uma determinada área, em um determinado espaço de tempo". Em linhas gerais, para a realização dessas pesquisas sobre pesquisas, é necessária a escolha de bases de dados para a captação do material a ser analisado; a delimitação do tempo do escopo da pesquisa; a definição dos metadados, os descritores da busca (palavras-chaves), de forma a orientar/delimitar o campo de pesquisa; e a definição dos critérios de seleção do material bibliográfico que irá compor o corpus de análise; posteriormente, temos a leitura desse corpus na tentativa de elaborar uma síntese preliminar deste material, à luz dos objetivos do pesquisador na construção do estado do Conhecimento; e, por fim, "sistematizar esses achados identificando possíveis tendências dos temas abordados a partir do processo de categorização" (ROMANOWSKI, 2002, p. 15).

\section{A QUALIDADE DA EDUCAÇÃO SUPERIOR À LUZ DOS PRINCÍPIOS DE ESTADO DO CONHECIMENTO: PRIMEIROS ACHADOS E CONSTRUÇÕES}

Os Estados do Conhecimento se apresentam junto à comunidade de pesquisadores a partir de diferentes perspectivas (FERREIRA, 2002; FIORENTINI; LORENZATO, 2007; MELLO, 2006; MOROSINI, 2015; ROMANOWSKI, 2002), e essas perspectivas se mostram a partir do operacional 
nessa execução. Dentro das possibilidade apresentadas, apoiamo-nos no entendimento de Morosini (2015); essa perspectiva de composição do Estado do Conhecimento se consubstancia a partir de três fases ou etapas metodológicas, que podem ser percebidas na construção de distintas bibliografias, a saber: Bibliografia Anotada, Bibliografia Sistematizada e a Bibliografia Categorizada (MOROSINI; NASCIMENTO, 2017). Cada uma dessas bibliografias representa diferentes níveis de aprofundamento dentro do tempo a ser investigado junto à proposição de construção de Estados de Conhecimentos.

A Bibliografia Anotada é o momento dentro do processo metodológico em que as delimitações do estudo são construídas e definições quanto à utilização de bases de dados, escopo da investigação, objetivos e a escolha dos critérios de captação dos materiais bibliográficos - incluindo seu tipo - são apresentados. Em nossa investigação, optamos por utilizar como base de dados na captação do material bibliográfico (teses e dissertações) a Biblioteca Digital Brasileira de Teses e Dissertações do Instituto Brasileiro de Informação em Ciência e Tecnologia $(\mathrm{BDTD} / \mathrm{IBICT})^{3}$, já que a mesma possui representatividade na acreditação oficial, no Brasil, e sua abrangência nacional, pois inclui todos os programas de pós-graduação credenciados no país e oferece livre acesso na web ${ }^{4}$. Utilizamos a busca avançada junto ao BDTD/IBICT, a partir da inserção do metadado (descritor) qualidade da educação, alinhado ao assunto educação superior, com recorte temporal de 10 anos (2007-2017), na busca por captar o que há de recente no entendimento desse campo de estudos.

Ao todo, localizamos nesta investigação 398 documentos; a partir de uma leitura flutuante, percebemos que muitos dos trabalhos captados, acabam escapando do escopo de nossa investigação; dessa forma, tiveram de ser retirados, excluídos da constituição do corpus de análise. Utilizamos como gatilho na busca pelo material bibliográfico os descritores educação superior e qualidade da educação; para esses, por sua vez, se compreendermos a semântica presente nas expressões a partir de sua unitarização, abrem-se outras perspectivas, das quais, entretanto, acabam emergindo aspectos distintos daqueles colocados a evidenciar nesta investigação. Desses 398 trabalhos encontrados, após utilizamos os critérios

3

Atualmente a base de dados da Biblioteca Digital Brasileira de Teses e Dissertações do Instituto Brasileiro de Informação em Ciência e Tecnologia (BDTD/IBICT) reúne um total de 109 Instituições de Educação Superior, 349.047 dissertações de mestrado e 169.848 teses de doutorado, respectivamente, totalizando desta forma, um banco de dados com 518.894 documentos disponíveis.

4 A Biblioteca Digital Brasileira de Teses e Dissertações do Instituto Brasileiro de Informação em Ciência e Tecnologia (BDTD/IBICT) utiliza a tecnologia do Open Archives Initiative (OAI), integrando os sistemas de informação dos diferentes Programas de Pós- Graduação brasileiros avaliados pela Coordenação de Aperfeiçoamento de Pessoal de Nível Superior (CAPES) e constituindo um catálogo nacional de teses e dissertações a partir dos respectivos metadados disponibilizados pelas Instituições de Ensino Superior. 
de seleção, compuseram o corpus de análise 70,10\%; em números absolutos, o corpus de analise se constitui a partir de duzentas e setenta e nove investigações (Tabela 01).

Tabela 01 - Representação da constituição do corpus de análise, a partir da construção da Bibliografia Anotada, evidenciando a quantidade de documentos captados junto à base de dados da BDTD/IBICT.

\begin{tabular}{|c|c|c|c|c|}
\hline $\begin{array}{c}\text { BASE DE } \\
\text { DADOS }\end{array}$ & $\begin{array}{c}\text { METADADOS } \\
\text { DESCRITORES }\end{array}$ & $\begin{array}{c}\text { PARÂMETROS } \\
\text { DE BUSCA }\end{array}$ & $\begin{array}{c}\text { DOCUMENTOS } \\
\text { ENCONTRADOS }\end{array}$ & $\begin{array}{c}\text { DOCUMENTOS } \\
\text { UTILIZADOS }\end{array}$ \\
\hline \multirow{2}{*}{ BDTD/IBICT } & Educação Superior & \multirow{2}{*}{$\begin{array}{c}\text { Busca avançada } \\
\text { Assunto }\end{array}$} & 129 & 116 \\
\cline { 2 - 3 } & $\begin{array}{c}\text { Qualidade da } \\
\text { Educação }\end{array}$ & Educação Superior & 269 & 163 \\
\hline \multicolumn{2}{|l|}{ TOTAL DE DOCUMENTOS LOCALIZADOS } & 398 & 279 \\
\hline
\end{tabular}

Seguindo a produção dos dados a partir da construção de Estados do Conhecimento, partimos para o desenvolvimento da Bibliografia Sistematizada, onde fazemos um detalhamento analítico maior do material que compõe o corpus de análise (a priorn), a partir da leitura aprofundada do material bibliográfico, na busca de identificar os objetos de estudo privilegiados no corpus de análise, as metodologias e abordagens impregnadas e seus respectivos referenciais. Algumas questões, emergem nesse momento da pesquisa, como por exemplo, os níveis de elaboração no qual estas pesquisas (dissertações ou teses) se mostram conforme o gráfico 1 .

Gráfico 01 - Distribuição do corpus de análise em função dos níveis relativos as produções bibliográficas.

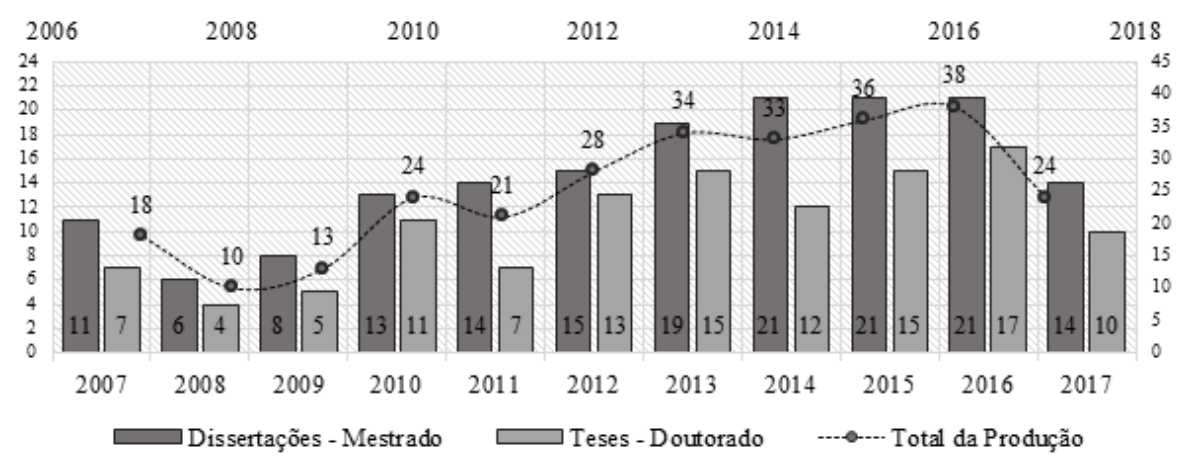


Com relação ao nível da Pós-Graduação que os estudos componentes do corpus de análise se mostram, percebemos que as produções bibliográficas do tipo dissertação ganham destaque em relação às teses, pois elas, no período (20072017), colocam-se quantitativamente em número superior (163 dissertações e 116 teses). Na produção das dissertações, temos, em 2007, 18 estudos; já, no ano seguinte, tivemos um pequeno declínio em seu quantitativo ( 6 trabalhos), seguido de um crescente até 2013 (respectivamente, 8 trabalhos em 2009, 13 trabalhos em 2010, 14 trabalhos em 2011, 15 trabalhos em 2012, e 19 trabalhos em 2013), quando a produção se estabiliza até o ano de 2016 (21 trabalhos em 2014, 2015 e 2016), com um declínio em 2017 (14 trabalhos).

No que se refere à produção bibliográfica no formato de teses, não encontramos o mesmo formato em sua distribuição quantitativa. Inicia-se o período analisado (2007) com 7 teses, período este seguido de um declínio de trabalhos em 2008 (4 investigações), com um aumento em 2009 e 2010 (respectivamente cinco e 11 estudos). Em 2011 há novamente uma diminuição desta produção (sete trabalhos), seguindo de um aumento em 2012 e 2013 (13 e 15 estudos), em 2014 há mais um declínio (dois trabalhos), nos anos subsequentes 2015 e 2016 um novo crescente emerge (15 e 17 investigações), e no último ano do período, 2017, temos mais um decréscimo (dez estudos). O platô destas produções se apresenta em diferentes momentos próximo, indicando uma tendência: as dissertações de mestrado tiveram seu ápice nos anos de 2014, 2015 e 2016 (com 21 estudos por ano); já as teses de doutorado, atingem seu máximo em 2016. A partir desses dados, podemos inferir que existiu, por parte das comunidades de pesquisa, um interesse em particular pela temática entre os anos de 2013 e 2016; quando as investigações em nível de mestrado (dissertações) ganham destaque; este período de 4 anos representa cerca de $53,5 \%$ de toda a produção dos dez anos.

E, por fim, após as construções de Bibliografias Anotadas e Sistematizadas, temos a Bibliografia Categorizada, momento que pode ser definido como o instante em que são mobilizados - por parte do pesquisador - seus referencias teóricos de domínio do campo, consolidando-se, nesse momento. a percepção do campo de investigação. Podemos ainda apontar que essa é a etapa mais criativa presente no processo, pois as categorias a serem utilizadas na leitura do corpus de análise, seja com categorias definidas a priori (as categorias assumidas pelo pesquisador antes do contato com o material em análise), seja com uma categorização a partir dos dados, a posteriori (categorias que emergem a partir do material em análise). Segundo Moraes (2003, p. 193), "toda leitura é feita a partir de uma perspectiva teórica"; diferentes olhares possibilitaram novas perspectivas de sentido ao corpus de análise, o que contribuiu de forma significativa para o processo de categorização. 
Acreditamos, nesse sentido, utilizar neste este estudo, no processo de categorização, a perceptiva das categorias a posteriori no entendimento do campo, por acreditamos que, junto a estes "casos", uma emergência surgirá, principalmente a partir do conceito polissêmico dado à expressão qualidade. No processo de construção da Bibliografia Sistematizada, porém, percebemos que o material analisado trazia (em diferentes dimensões) constructos bazilares de categorias teóricas clássicas, já conhecidas pela comunidade de pesquisa, como aquelas trazidas por Pedro Demo (DEMO; 1985, 2001). Dessa forma, optamos por utilizar como referencial as categorias clássicas de análise e de enquadramento dos conceitos de qualidade. Nesse sentido, nossas analises sintonizam-se com os conceitos de qualidade acadêmica, qualidade social e qualidade educativa, que Demo $(1985$;2001) elabora para referir-se à qualidade da educação superior e à qualidade da instituição universitária (DAVOK, 2007).

\section{A QUALIDADE DA EDUCAÇÃO SUPERIOR NA PERSPECTIVA DA PRODUÇÃO ACADÊMICA (2007-2017)}

No processo de categorização, os trabalhos foram distribuídos à luz das três construções teóricas citadas anteriormente, sendo os estudos alocados nessas categorias. A qualidade acadêmica pode ser definida como sendo "a capacidade de produção original de conhecimento, da qual depende intrinsecamente à docência" (DEMO, 1985, p. 35). Dessa forma, aqui temos a ideia de qualidade alinhada à capacidade criativa de produção de conhecimento característica da Educação Superior, a partir do desenvolvimento da pesquisa cientifica. A qualidade acaba estando intimamente ligada à capacidade que os docentes desenvolvem na "transmissão" dos conhecimentos produzidos a partir de suas atividades de pesquisa, orientação, tratamento teórico no entendimento dos fenômenos e problemáticas sociais.

A qualidade social, desenvolve-se a partir de um outro olhar, sendo compreendida por Demo (1985, p. 37-38) como sendo “a capacidade de identificação comunitária, local e regional, bem como com relação ao problema do desenvolvimento. (...) Trata-se de colocar à universidade a necessidade de ser consciência teórica e prática do desenvolvimento". Essa perspectiva de qualidade se mostra essencialmente a partir da cultura instituída sobre a função das instituições universitárias na devolução do investimento nela realizado pela sociedade. Podemos perceber estes processos no contexto das atividades extensionistas, nos estágios curriculares e atividades extraclasse promovidas pelas instituições universitárias, de forma que suas práticas possam intervir de fato na 
realidade social onde também elas se inserem. Essa qualidade se mostra a partir da oportunidade que a Educação Superior possibilita ao seu alunado com o contato da prática contextualizada pela teoria.

Já a qualidade educativa tem por base por outros referentes, efetivandose na "formação da elite, no sentido educativo. A universidade também educa" (DEMO, 1985, p. 39). A qualidade educativa se mostra pela capacidade que possuem as instituições de ensino de empreender seus esforços na formação plena dos sujeitos, como por exemplo o estimulo à formação de professores nos diferentes níveis de ensino, em programas de formação de gestores educacionais no manuseio da coisa pública, líderes comunitários, entre outros. O foco está na formação do cidadão que cuida para que a sociedade seja democraticamente organizada e se desenvolva em seus aspectos econômico, institucional, político e cultural.

A partir dos dados produzidos com auxílio da estratégia de construção de Estados do Conhecimento, foi possível que "enquadrássemos" os estudos bibliográficos componentes do corpus de análise, nas categorias teóricas anteriormente citadas; dessa forma, temos então a síntese deste estudo (Tabela 02). A maioria (48,02\%) dos estudos que compõem o quadro analítico se apresentam a partir do entendimento de qualidade a partir dos processos de formação dos sujeitos, nas mais diferentes esferas nas quais atuam (qualidade educativa). Aqui encontramos estudos que percebem a qualidade a partir dos fenômenos da formação de professores e dos processos de ensino-aprendizagem desenvolvidos na Educação Superior. Os trabalhos aqui postos expõem o potencial humano desenvolvido no contexto universitário a partir das diferentes articulações entre conhecimento e formação exaltados neste espaço.

\section{Tabela 02 - Distribuição do corpus de análise captado junto à base de dados da BDTD/IBICT em relação às categorias teóricas balizadas da investigação.}

\begin{tabular}{|c|c|c|}
\hline CATEGORIAS & $\mathbf{n}$ & \%APR \\
\hline Qualidade Acadêmica & 93 & 33,35 \\
\hline Qualidade Social & 52 & 18,63 \\
\hline Qualidade Educativa & 134 & 48,02 \\
\hline TOTAL & $\mathbf{2 7 9}$ & 100,00 \\
\hline
\end{tabular}

A qualidade acadêmica $(33,35 \%)$ se mostra representando mais de um quarto dos estudos que compõem o corpus de análise, consubstancia-se na relação entre o papel da universidade, a prática dos seus docentes-pesquisadores, as 
pesquisas desenvolvidas junto ao docente-pesquisador e a sua prática docente. Os trabalhos reunidos nessa categoria, trazem a qualidade a partir da formação intelectual do docente-pesquisador aditiva à formação do seu alunado (graduação e pós-graduação), em diferentes espaços acadêmicos. Pois nessa perspectiva, a qualidade da Educação Superior está intimamente ligada ao trânsito formativo de seus docentes, e o "produto" por eles oferecido no itinerário formativo dos seus alunos.

Em menor quantidade (18,63\%), temos a qualidade da Educação Superior a partir de uma perspectiva bastante distinta, pois esta não se relaciona exclusivamente com o conhecimento produzido no espaço universitário, mas se focaliza no impacto desse conhecimento na comunidade acadêmica. A qualidade social se apresenta principalmente a partir de estudos e investigações acerca das atividades de extensão desenvolvidas junto ao cenário universitário. A qualidade social se manifesta - neste cenário de pesquisa - à luz das estratégias utilizadas pelas diferentes Instituições de Ensino Superior para "devolver" à sociedade, os impostos nelas investidos (de forma direta, isenções fiscais, entre outros). A qualidade da Educação Superior, nesse sentido, está na inserção na comunidade, junto ao seu "local", fazendo com que a teoria experienciada nas dependências da instituição se materialize no desenvolvimento de práticas sociais.

\section{ALGUMAS CONSIDERAÇÕES}

As pesquisas denominadas Estado do Conhecimento se mostram como importante ferramenta dentro dos processos de construção do conhecimento, em especial nas Ciências Humanas e Sociais, que acabam carecendo de pesquisas sobre as pesquisas. Este resgate permite que uma série de elementos que caracterizam a pesquisa acadêmica sejam evidenciados e situados no tempo e no espaço no qual foram construídos, como: os temas/temáticas privilegiados; abordagens e posturas adotadas no desenvolvimento dos estudos; além da percepção do campo que está sendo exposto à luz da investigação. Pensamos, ainda, que esse movimento se constitui de extrema importância nas aproximações dos jovens pesquisadores (mestrandos e doutorandos) às suas temáticas de pesquisa, devendo ainda ser estimulados pelas comunidades de pesquisa acadêmica. Dessa forma, o estudo aqui apresentado se constitui como um primeiro impulso de aproximação com as diferentes dimensões de pesquisa, na qual os conceitos de qualidade mostram que as categorias teóricas que utilizamos trazem em si uma possibilidade de entendimento sobre o fenômeno da qualidade junto à produção acadêmica (teses e dissertações) de Programas de Pós-Graduação stricto senso brasileiros. 
Acreditamos que as dimensões de qualidade (acadêmica, educativa e social) que elencamos para o entendimento do fenômeno estudado acabam por explicitar a complexidade na qual a polissemia do termo se encontra nas produções bibliográficas de Programas de Pós-Graduação stricto sensu brasileiros (dissertações e teses), evidenciando que mesmo no contexto universitário, não existe um consenso por parte da comunidade de pesquisadores sobre uma definição clara de qualidade. Percebemos que as transformações que ocorrem no uso do termo se apresentam, particularmente, em função do destaque a ser evidenciado no fenômeno, interseccionado a qualidade, como por exemplo, a qualidade no contexto da Educação Superior.

Do material analisado, a maior parte resultado de dissertações de mestrado, percebemos que a produção sobre a temática alcançou seu máximo em 2016 (38 estudos); porém, o período de 2013 e 2015 também possui relevância nesse enquadramento. A maioria dos estudos que compõem o corpus de análise, debruçase sobre o entendimento da qualidade da Educação Superior na perspectiva da qualidade educativa, ou seja, esse conjunto de estudos (aproximadamente 48\%) apresenta problemáticas e/ou fenômenos que trazem em si uma relação entre qualidade e o papel do espaço universitário na formação plena dos sujeitos (no sentido educativo), com estímulos à autonomia e à participação ativa na sociedade. Em outro conjunto de trabalhos (aproximadamente 33\%), relaciona-se a qualidade da Educação Superior, a quadros docentes especializados nos diferentes espaços universitários, a qualidade acadêmica.

Nesse sentido, o espaço universitário se coloca como o lócus de produção do conhecimento na sociedade, e este espaço, por sua vez, depende intrinsecamente da capacidade docente na "transmissão" destes saberes desenvolvidos, particularmente pela sua expertise em pesquisa. Um aspecto diferente do que os estudos anteriores evidenciaram está na perspectiva da qualidade da Educação Superior, a partir da "devolutiva" do trabalho desenvolvido no campo acadêmico à sociedade, qualidade social. Essa forma de perceber a qualidade da Educação Superior ainda é pouco explorada nos trabalhos (aproximadamente 19\%), pois aqui fica evidenciada a relação existente entre a universidade e sua identificação com o local (comunidade acadêmica).

Uma próxima etapa a ser focalizada a partir da produção deste estudo, está em identificar as comunidades de pesquisa produtoras de conhecimento dentro da temática da qualidade da Educação Superior, da mesma forma que perceber quais são dos Programas de Pós-Graduação brasileiros onde essas comunidades se inserem, buscando ainda, compreender os referenciais epistemológicos que norteiam essas investigações. Procuramos com este trabalho, observar o fenômeno da qualidade a partir dos diferentes momentos nos quais a polissemia do termo 
se constitui, destacando a percepção da comunidade de pesquisadores brasileiros sobre os usos, as adequações e as (re)significações que a qualidade da Educação Superior, tanto como ideia como conceito, vem sofrendo ao longo do tempo.

\section{REFERÊNCIAS}

BOURDIEU, P. O campo científico. São Paulo: Ática, (Coleção Os Pensadores) 1988.

CORTESÃO, L.; STOER, S. Cartografando a transnacionalização do campo educativo: o caso português. In: SANTOS, Boaventura de Sousa. A globalização e as ciências sociais. São Paulo: Cortes, p. 377-414, 2002.

CUNHA, M.I. da. Qualidade da educação superior e a tensão entre democratização e internacionalização na universidade brasileira. Revista Avaliação, v. 22, n. 03, p. 817-832, nov. 2017. Acesso em: 10 jul 2018, Disponível em: <https://goo.gl/ $\mathrm{NgFtj} 5>$.

DAVOK, D. F. Qualidade em Educação. Revista Avaliação, Campinas; Sorocaba, SP, v. 12, n. 3, p. 505-513, set. 2007. Acesso em: 03 ago 2018, Disponível em: $<$ https://goo.gl/qxvEMq>.

DEMO, P. Educação e qualidade. 6. ed. São Paulo: Papirus, 2001.

DEMO, P. Ciências sociais e qualidade. São Paulo: ALMED, 1985.

FERREIRA, N. S. de. A. As Pesquisas Denominadas “Estado da Arte”. Educação \& Sociedade, ano XXIII, n. 79, ago, 2002. Acesso em: 05 ago 2018, Disponível em: <https://goo.gl/Xej6j1>.

FIORENTINI, D.; LORENZATO, S. Investigação em Educação Matemática: Percursos Teóricos e Metodológicos. 2 ed. Campinas: Autores Associados, 2007.

FONSECA, J. J. S. Metodologia da pesquisa científica. Fortaleza: UEC, 2002. 
FONTOURA, J. S. D. A. A Gestão da Educação Superior em Contextos Emergentes: A Perspectiva dos Coordenadores dos Cursos Superiores de Tecnologia do IFRS - Campus Porto Alegre. 2018, 204 f. Dissertação (Mestrado em Educação) - Pontifícia Universidade Católica do Rio Grande do Sul, Porto Alegre, 2018. Disponível em: < https://goo.gl/ynYL5U>. Acesso em: 22 jul. 2018.

MAINARDES, J.; TELLO, C. A pesquisa no campo da política educacional: Explorando diferentes níveis de abordagem e abstração. Arquivos Analíticos de Políticas Educativas, v. 24, no 75, p. 1-16, jul. 2016. Disponível em: <https:// goo.gl/gkF5Dn>. Acesso em: 7 ago 2018.

MELO, M. V. Três décadas de Pesquisa em Educação Matemática na Unicamp: Um Estudo Histórico a partir de Teses e Dissertações. 2006. 230 f. Dissertação (Mestrado em Educação) - Universidade Estadual de Campinas, Campinas, 2006. Disponível em: <https://goo.gl/QmjwJd>. Acesso em: 29 jul 2018.

MORAES, R. Uma tempestade de luz: a compreensão possibilitada pela análise textual discursiva. Ciência \& Educação, v. 9, n. 2, p. 191-211, 2003. Disponível em: <https://goo.gl/9xQhFf>. Acesso em: 13 jul 2018.

MOROSINI, M. C. Estado de conhecimento e questões do campo científico. Revista Educação. Santa Maria, v. 40, n. 1, p. 101-116, jan./abr. 2015. Disponível em: <https://goo.gl/wyJMzB>. Acesso em: 13 jul 2018.

MOROSINI, M. C. Qualidade da Educação Superior em Contextos Emergentes. Revista Avaliação, Campinas; Sorocaba, SP, v. 19, n. 2, p. 385-405, jul. 2014. Disponível em: <https://goo.gl/aiWzzD>. Acesso em: 20 jul 2018.

MOROSINI, M. C. Internacionalização na Produção de Conhecimento em IES Brasileiras: Cooperação Internacional Tradicional e Cooperação Internacional Horizontal. Educação em Revista, v. 27, n. 01, p.93-112, abr. 2011. Disponível em: < https://goo.gl/iBqMPv>. Acesso em: 15 jul 2018.

MOROSINI, M. C.; FERNANDES, C. M. B. Estado do Conhecimento: conceitos, finalidades e interlocuções. Educação Por Escrito, Porto Alegre, v. 5, n. 2, p. 154-164, jul.-dez. 2014. Disponível em: < https://goo.gl/zhGzgB>. Acesso em: 15 jul 2018. 
MOROSINI, M. C.; NASCIMENTO, L. M. do. Internacionalização da Educação Superior no Brasil: A Produção Recente em Teses e Dissertações. Educação em Revista, Belo Horizonte, n. 33, 2017. Disponível em: <https://goo.gl/7Skc8c>. Acesso em: 28 jul 2018.

ROMANOWSKI, J. P. Licenciaturas no Brasil: Um Balanço das Teses e Dissertações (1990- 1998). 2002. 132 f. Tese (Doutorado em Educação) Universidade de São Paulo, São Paulo, 2002. Disponível em: < https://goo.gl/ Ms74To >. Acesso em: 11 jul 2018.

SANDER, B. Administração da Educação no Brasil: Genealogia do Conhecimento. Brasilia: Liber Livro, 2007.

SOBRINHO, J. D. Avaliação e Transformações da Educação Superior Brasileira (1995-2009): do Provão ao SINAES. Revista Avaliação, Campinas; Sorocaba, SP, v. 15, n. 1, p. 195-224, mar. 2010. Disponível em: <https://goo.gl/TxnxWm>. Acesso em: 03 jul 2018.

TELLO, C.; MAINARDES, J. La posición epistemológica de los investigadores en Política Educacional: debates teóricos en torno a las perspectivas neo-marxista, pluralista y posestructuralista. Archivos Analíticos de Políticas Educativas, v. 20, n. 9, mar. 2012. Disponível em: < https://goo.gl/dbts1g>. Acesso em: 05 jul 2018.

TELLO, C.; MAINARDES, J. Revisitando o enfoque das epistemologias da política educacional. Práxis Educativa, Ponta Grossa, v. 10, n. 1, p. 153-178, jan./jun. 2015. Disponível em: <https://goo.gl/xzfRjs>. Acesso em: 05 jul 2018.

\footnotetext{
JULIAN SILVEIRA DIOGO DE ÁVILA FONTOURA é licenciado em Ciências da Natureza: Biologia e Química pelo Instituto Federal de Educação, Ciência e Tecnologia - IFRS (2015), Mestre em Educação pelo Programa de PósGraduação em Educação da Escola de Humanidades da Pontifícia Universidade Católica do Rio Grande do Sul - PUCRS (2018), Doutorando do Programa de Pós-Graduação em Educação da Universidade do Vale do Rio dos Sinos UNISINOS, Bolsista CAPES/PROEX, desenvolvendo investigações junto a Linha de Pesquisa Educação, História e Políticas, com pesquisas centradas majoritariamente nas temáticas: Educação Superior, Gestão da Educação; Contextos Emergentes; e Qualidade da Educação. Atua como Professor da área de Ciências da Natureza da Rede Pública de Educação do Estado do Rio Grande do Sul. E-mail: julian.diogo@gmail.com
} 
BERENICE CORSETTI possui Graduação em História pela Universidade de Caxias do Sul - UCS (1968), Mestrado em História pela Universidade Federal Fluminense - UFF (1983), Doutorado em Educação pela Universidade Estadual de Campinas - UNICAMP (1998) e Pós-Doutorado em Educação pela Universidade Estadual de Campinas - UNICAMP (2010). É bolsista de Produtividade em Pesquisa do CNPq. Atualmente é professora titular da Universidade do Vale do Rio dos Sinos - UNISINOS, integrando o corpo docente permanente do Programa de Pós-Graduação em Educação. É a atual coordenadora da Linha de Pesquisa I (Educação, História e Políticas), deste Programa. Desenvolve pesquisas na área de História das Políticas Educacionais no Brasil, relacionadas ao contexto internacional; Indicadores de Qualidade da Educação no Brasil e História da Educação. Atua nos cursos de Licenciaturas da UNISINOS, em disciplinas que relacionam a História da Educação e as Políticas Educacionais. E-mail: bcorsetti@unisinos.br

Recebido em agosto de 2018 Aprovado em novembro de 2018 